\title{
Transfer of performance to new comparison choices following differential outcome matching-to-sample
}

\author{
PETER J. URCUIOLI, THOMAS B. DEMARSE, and KAREN M. LIONELLO \\ Purdue University, West Lafayette, Indiana
}

\begin{abstract}
Four experiments examined transfer of differential outcome performances to new choice responses in pigeons. Experiments $1 \mathrm{~A}$ and $1 \mathrm{~B}$ showed that new responses trained off a matching-to-sample baseline readily substituted for the choice alternatives in differential outcome matching, provided that they shared the same outcome associations as the alternatives they replaced. Experiment 2 showed that comparison responses trained on baseline, but in a task in which their different outcomes occurred equally often following each sample (viz., one-to-many matching), substituted for the choices in a standard, differential outcome task. Experiment 3 showed, somewhat surprisingly, that the choices in the latter task were likewise effective substitutes in one-to-many matching. These results pose separate challenges for standard two-process theory and for the bidirectional account of differential outcome performance, and they suggest other cues that pigeons may use to predict outcomes.
\end{abstract}

In instrumental differential outcome tasks, the reinforcer for each response alternative differs across those alternatives. This situation is unlike typical instrumental and operant procedures in which all responses produce the same reinforcer. The differential outcome paradigm has attracted considerable empirical and theoretical interest since Trapold's (1970) demonstration that discrimination learning proceeds more rapidly when different responses produce different reinforcers than when they produce the same one. At the time, Trapold pointed out that this finding showed that the reinforcers for instrumental learning serve more than just a motivational role-in addition, they ostensibly give rise to reward expectancies that can then act as discriminative stimuli. A great deal of subsequent research has confirmed Trapold's original findings (e.g., Carlson \& Wielkiewicz, 1976; DeLong \& Wasserman, 1981; Fedorchak \& Bolles, 1986; Peterson, 1984; Urcuioli, 1990) and has provided independent support for his outcome expectancy explanation (e.g., Edwards, Jagielo, Zentall, \& Hogan, 1982; Honig, Matheson, \& Dodd, 1984; Peterson, 1984; Urcuioli, 1990, 1991; Urcuioli \& DeMarse, 1996). This explanation, also known as the two-process account of differential outcome performance, states that (1) reward (outcome) expectancies are conditioned to stimuli that signal which reinforcer is contingent on responding, and (2) behavior then comes under discriminative control of those expectancies by virtue of reinforced responding in their presence. In line with this reasoning, studies have

This research was supported by National Science Foundation Grant IBN-9419929 to the first author. Correspondence should be addressed to P. J. Urcuioli, Department of Psychological Sciences, Purdue University, 1364 Psychology Building, Room 3180, West Lafayette, IN 47907-1364 (e-mail: uche@psych.purdue.edu). shown that, following acquisition of a differential outcome task, performances transfer to new stimuli signaling the same outcomes even though those stimuli have no explicit reinforcement history with respect to responding (e.g., Peterson, 1984; Urcuioli, 1990; Urcuioli, DeMarse, \& Zentall, 1998).

In the present experiments, we examined another type of transfer of control previously reported in the literature but that, for reasons that will become clearer, does not readily fit the outcome expectancy explanation-namely, transfer of performance to new responses. The specific empirical question we addressed was: Will pigeons transfer differential outcome matching-to-sample to new comparison alternatives (new "choice responses") that have been associated with the same outcomes as those they replace?

Previous instrumental learning studies indicate that the answer to this question is "yes." For example, Colwill and Rescorla (1988, Experiment 1) showed that in a freeoperant differential outcome task with rats, the nominal discriminative stimuli $\left(\mathrm{S}^{\mathrm{D}} \mathrm{s}\right)$ immediately transferred their control to new responses that had been differentially associated with the same outcomes in the absence of the $\mathrm{S}^{\mathrm{D}} \mathrm{s}$. For example, some rats initially received sucrose for making nose-poke responses in the presence of a light and received pellets for making handle-pull responses in the presence of a noise. Afterwards, sucrose was delivered for bar pressing and pellets were delivered for chain pulling while no lights or tones were presented. In a subsequent transfer test conducted in extinction, Colwill and Rescorla again presented the light and noise stimuli but this time in the context of a choice between the new responses (i.e., bar pressing and chain pulling). They found that, relative to the (nonreinforced) intertrial interval, each $\mathrm{S}^{\mathrm{D}}$ preferentially facilitated the rate at which rats made the response with which it shared a common 
Table 1

A Schematic of the Transfer-of-Control Designs

Used by Edwards et al. (1982, Experiment 1) and

by Colwill and Rescorla (1988, Experiment 1)

\begin{tabular}{|c|c|c|}
\hline \multicolumn{2}{|c|}{ Training } & \multirow[b]{2}{*}{ Transfer Tes } \\
\hline Task 1 & Task 2 & \\
\hline
\end{tabular}

$\begin{array}{lcc} & \text { Edwards et al. (1982) Study } \\ \mathrm{S} 1 \rightarrow \mathrm{R} 1(\mathrm{O} 1) & \mathrm{S} 3 \rightarrow \mathrm{R} 3(\mathrm{O} 1) & \mathrm{S} 1 \rightarrow \mathrm{R} 3 \\ \mathrm{~S} 2 \rightarrow \mathrm{R} 2(\mathrm{O} 2) & \mathrm{S} 4 \rightarrow \mathrm{R} 4(\mathrm{O} 2) & \mathrm{S} 2 \rightarrow \mathrm{R} 4 \\ & \text { Colwill \& Rescorla (1988) Study } \\ \mathrm{S} 1 \rightarrow \mathrm{R} 1(\mathrm{O} 1) & \mathrm{R} 3 \rightarrow \mathrm{O} 1 & \mathrm{~S} 1 \rightarrow \mathrm{R} 3 \\ \mathrm{~S} 2 \rightarrow \mathrm{R} 2(\mathrm{O} 2) & \mathrm{R} 4 \rightarrow \mathrm{O} 2 & \mathrm{~S} 2 \rightarrow \mathrm{R} 4\end{array}$

Note-S1-S4 = sample or discriminative stimuli. $\mathrm{R} 1-\mathrm{R} 4=$ responses. $\mathrm{O} 1$ and $\mathrm{O} 2=$ outcomes.

outcome. In other words, if the light had previously signaled sucrose reinforcement, it elevated responding to the alternative (bar pressing) that had produced sucrose in the off-baseline phase. Likewise, if the noise had previously signaled pellet reinforcement, it elevated responding to the alternative (chain pulling) that had produced pellets. By contrast, response rates to the alternatives associated with the opposite outcome were not enhanced relative to the intertrial interval.

Analogous results were obtained by Edwards et al. (1982) in pigeons' matching-to-sample. They initially trained pigeons to high levels of accuracy on two differential outcome tasks involving the same outcomes (corn and wheat) but different sample stimuli and different comparison responses. Following acquisition of both matching tasks, Edwards et al. substituted the comparisons from one task for those used in the other and found that the samples selectively cued the "new" choice responses with which they shared a common outcome. Given that these results were obtained in the matching paradigm, they indicate that the empirical question posed above has, in fact, already been answered (in the affirmative). However, the design of the Edwards et al. experiment, shown schematically in the top half of Table 1, can be viewed somewhat differently.

Specifically, instead of a test of transfer to new comparison choice responses, the Edwards et al. design can also be viewed as a test of transfer to new sample stimuli. In other words, rather than interpreting the results as evidence for the ability of an existing set of sample stimuli (S1 and S2) to transfer their control to new comparison responses (R3 and R4), one can just as easily consider the findings as evidence that the control exerted by one set of samples (S3 and S4) over existing responses (R3 and R4) transfers to new stimuli (S1 and S2). This may sound like a purely semantic distinction, but it turns out to have important theoretical ramifications. For instance, viewed as a test of transfer across sample stimuli, the Edwards et al. results are quite consistent with Trapold's two-process account. In other words, assuming that each set of samples in training gives rise to differential outcome expectancies and that those expectancies have acquired discriminative control over the choices in each task, then it should not matter which samples generate the controlling expectancies. In short, choices involving either comparison set should be appropriately cued by any other samples that generate the same differential outcome expectancies.

By contrast, the Colwill and Rescorla (1988) study, shown schematically in the bottom half of Table 1, cannot be viewed in quite the same fashion. Note that, in their second training task, there were no explicit $\mathrm{S}^{\mathrm{D}} \mathrm{S}$ for the newly introduced responses. As a consequence, the twoprocess (outcome expectancy) account has difficulty predicting that the control over responding acquired by $\mathrm{S} 1$ and S2 in initial training should transfer to R3 and R4 in testing. The reason for this difficulty is that, in order for such transfer to materialize, R3 and R4 must, in training, come under discriminative control of the same outcome expectancies presumably conditioned to S1 and S2 in the initial task. But the absence of any explicit $S^{D} S$ in the second task seems to preclude this, thus removing the basis for transfer hypothesized by two-process theory. By similar logic, that theory would predict that pigeons would not transfer matching to new comparisons if those choices were trained in the same way that Colwill and Rescorla trained R3 and R4 (i.e., in the absence of explicit stimuli to which reward expectancies could be conditioned). On the other hand, the Colwill and Rescorla data suggest otherwise.

Moreover, an alternative to two-process theory makes the contrasting prediction that transfer of differential outcome matching to new comparison responses should occur even if those responses are trained in the absence of sample stimuli. Specifically, Rescorla and Colwill (1989; see also Rescorla, 1992) have postulated that animals are sensitive to the response-outcome $(\mathrm{R}-\mathrm{O})$ associations in differential outcome tasks (see Urcuioli \& DeMarse, 1997) and that these associations are bidirectional. This bidirectional hypothesis states that any stimulus that activates the outcome representation in an $\mathrm{R}-\mathrm{O}$ association will, via the "reverse" (viz., O-R) association, then activate the corresponding response (see, e.g., Urcuioli \& DeMarse, 1996). By this account, the selective facilitation of R3 by S1 and R4 by S2 observed in testing by Colwill and Rescorla (1988) arose because (1) S1 and S2 activated the $\mathrm{O} 1$ and $\mathrm{O} 2$ representations, respectively (as a result of Task 1 training), and (2) those representations activated $\mathrm{R} 3$ and $\mathrm{R} 4$ via the bidirectional $\mathrm{R}-\mathrm{O}$ associations that developed in Task 2 . This reasoning can straightforwardly explain the Edwards et al. (1982) data as well.

There are a number of reasons, then, to test for transfer to new comparisons in matching-to-sample using a design like that of Colwill and Rescorla (1988, Experiment 1). First, and perhaps foremost, such a test can potentially discriminate between the two theoretical accounts described above. An unembellished two-process account predicts no transfer to new choice responses if those responses are trained off the matching baseline (i.e., in the absence of sample stimuli), whereas the bidirectional account does predict transfer. Although one might argue that the Colwill and Rescorla (1988) data have settled the issue, another test of the opposing pre- 
dictions in the context of a procedure so routinely used to study differential outcome effects (i.e., pigeons' matchingto-sample) is worthwhile. Second, all transfer-of-control studies in the matching literature of which we are aware can be interpreted as instances of sample substitutionthat is, in terms of the ability of new stimuli trained on or off baseline to replace the samples used in training. It seems only natural, then, to ask whether or not the transfer so often observed in these tests (e.g., Peterson, 1984; Urcuioli, 1990) can also be observed when the comparison choices are replaced by new alternatives that have been trained off baseline (i.e., in a way not amenable to interpretation as sample substitution). Third, such a test is relevant to whether or not comparison choices in matching-to-sample should legitimately be regarded as different "responses" in the same way that bar pressing versus nose poking are in free-operant studies (e.g., Colwill \& Rescorla, 1988; Rescorla, 1992, 1994). The comparisons are, after all, stimuli that birds peck in a (presumably) topographically similar fashion. Nonetheless, assuming that it is proper to consider comparison choices as different responses, then the bidirectional hypothesis clearly predicts transfer of matching to new choices. Consequently, evidence confirming this prediction would encourage continued use of this analogy (see, e.g., Colwill, 1994; Rescorla, 1994).

\section{EXPERIMENT 1A}

In Experiment 1A, we assessed the ability of new comparisons to substitute for those initially trained in differential outcome matching-to-sample. The distinctive feature of the present experiment was that the new choice responses were initially associated with different outcomes in the absence of sample stimuli. A control group received the same off-baseline training and the same differential outcome test but, for them, initial matching-to-sample training was conducted with both outcomes occurring randomly on all correct trials. If Colwill and Rescorla's (1988, Experiment 1) results are replicable within the matching context, then we expected that the group receiving differential outcome training would match above the level expected by chance $(50 \%)$ during the transfer test, whereas the nondifferential control group would match at or near chance levels.

\section{Method}

\section{Subjects}

Eight experimentally naive White Carneaux pigeons obtained from the Paimetto Pigeon Plant (Sumter, SC) served in the experiment. All pigeons were retired breeders and, prior to the experiment, were reduced to $80 \%$ of their free-feeding body weights by restricted feeding. Daily feeding was accomplished mostly in the experimental sessions except that food was provided in the home cage on the one day per week that sessions were not run and when the birds were unable to eat enough in a session to maintain their $80 \%$ weights. The pigeons were individually housed in stainless steel wire mesh cages in a temperature-controlled colony room on a 14:10-h light:dark cycle. Grit and water were always available in the home cages. They were randomly divided into two groups of 4 immediately prior to the experiment.

\section{Apparatus}

The experiment was conducted in a single BRS/LVE three-key pigeon chamber (Model PIP-016 panel housed inside an SEC-002 small animal enclosure). Behind each of the three, horizontally aligned $2.5-\mathrm{cm}$-diameter keys was a BRS/LVE inline stimulus projector equipped to project the following stimuli: three white vertical and three white horizontal lines on black backgrounds, a large white dot and an inverted white triangle on black backgrounds, and red, green, and white homogeneous fields (Pattern No. 692). The response keys were spaced $8.3 \mathrm{~cm}$ apart, center to center, and were positioned $10 \mathrm{~cm}$ below the top of the panel. A $5 \times 5.8 \mathrm{~cm}$ opening located about $13 \mathrm{~cm}$ below the center response key permitted access to a rear-mounted grain magazine. Raising the food hopper coincided with the illumination of a 24-ESB stimulus bulb located inside of the hopper housing. The bulb could also be lit independently of activation of the food hopper. A General Electric No. 1829 bulb located $7.6 \mathrm{~cm}$ above the center key and partially covered by a metal housing served as a houselight. The opening in the housing directed light from the bulb toward the ceiling. Ventilation and masking noise were provided by a blower fan mounted on the outside of the chamber. All experimental events were controlled and monitored by an IBM-PC XT located in an adjacent room.

\section{Procedure}

Preliminary training. After each bird had been trained to eat from a lit food hopper, it received three sessions of response shaping during which food was delivered contingent upon pecking the stimuli that would later appear as samples or comparisons in matchingto-sample. In the first session, the vertical and horizontal lines were each presented 30 times on the center key with a 10 -sec intertrial interval (ITI) separating successive presentations. A single peck to whichever line stimulus appeared on a trial immediately turned off the stimulus and produced $3-\mathrm{sec}$ access to grain. In the second session, the vertical and horizontal stimuli each appeared 10 times on the center key, and red and green hues appeared 10 times each on both the left and the right side keys. Again, a single peck to whichever key was lit by a line or a hue produced $3-\mathrm{sec}$ access to grain. The third session was conducted as the second except that the triangle and dot stimuli, instead of red and green, appeared on the side keys. In all sessions, the order of stimulus presentation was randomized, and the houselight remained on continuously.

Hue-choice pretraining. Next, every bird received five pretraining sessions with the stimuli that subsequently served as comparisons in matching-to-sample training. Each 60 -trial session involved single presentations of a red or green hue on the left or right side key. A single peck to the hue appearing on a trial immediately turned off the stimulus and produced either food reinforcement or lighting of the bulb inside of the hopper without raising the magazine ("no food"). If no peck occurred within $5 \mathrm{sec}$ of stimulus onset, the hue went off automatically, and the food or no-food outcome occurred. For the 4 birds in Group Differential, a single peck to red always produced one outcome (e.g., food), whereas a single peck to green always produced the other (e.g., no food). Hue-outcome assignments were balanced across birds. For the 4 birds in Group Nondifferential, food and no food were scheduled to occur equally often following each hue. The order of stimulus presentations was randomized with the constraint that each hue appear an equal number of times on each side key. Successive trials were separated by a $10-$ sec ITI, the first $9 \mathrm{sec}$ of which were spent in darkness. The houselight then came on for the last $1 \mathrm{sec}$ of the ITI and remained on until the end of the food or no-food outcome, at which point it was turned off. The duration of food reinforcement (and the corresponding no- 
Table 2

Average Numbers of Pecks $(\max =30)$ and Average Latencies to Peck ( $\max =5,000 \mathrm{msec}$ ) the Side-Key Hues and Side-Key Forms Associated With Food and/or No Food on the Last Session of Each Pretraining Phase in Experiment $1 \mathrm{~A}$ Hue Pretraining Form Pretraining

\begin{tabular}{lrrlrrr}
\hline Stimulus & No. of Pecks & Latency & & Stimulus & No. of Pecks & Latency \\
\hline \multicolumn{7}{c}{ Group Differential } \\
F & 28.5 & 825 & F & 30.0 & 602 \\
NF & 1.8 & 5,000 & NF & 1.3 & 5,000 \\
& \multicolumn{7}{c}{ Group Nondifferential } \\
R & 13.0 & 3,590 & F & 28.7 & 747 \\
G & 12.7 & 3,630 & NF & 0.0 & 5,000 \\
\hline
\end{tabular}

Note- $F=$ food-associated stimulus. $\mathrm{NF}=$ no-food-associated stimulus. $\mathrm{R}=$ red. $\mathrm{G}=$ green

food event) was constant in each pretraining session but varied between 1.8 and 6 sec across sessions, such that each bird's body weight was maintained as close to the $80 \%$ value as possible.

Matching-to-sample training. Next, all birds learned to match vertical and horizontal line samples to red and green hue comparisons. Each trial in an 80-trial session began with the onset of the houselight $1 \mathrm{sec}$ before the appearance of a white center-key stimulus. A single peck to this "trial-ready" stimulus immediately turned it off and, following a brief $(500-\mathrm{msec})$ delay, produced a center-key sample stimulus consisting of either the vertical or the horizontal lines. Three seconds after sample onset, the line sample went off automatically as red and green hues appeared on the adjacent side keys. A single peck to either the red or the green comparison stimulus turned both off and produced either food or no food if the choice was correct or an equivalent timeout period with the houselight turned off if the choice was incorrect. A 10-sec ITI then ensued, the first 9 sec of which were spent in darkness. When a bird's comparison choice was incorrect, the trial was repeated following the usual ITI (i.e., a correction procedure was in effect). However, choices on correction trials did not enter into the computation of matching accuracy. The four possible combinations of the two line samples with the two left-right configurations of the red and green comparisons were randomized within successive blocks of 20 trials, with the constraint that no combination occur more than three times in a row.

For half of the birds in each group, a red-comparison choice was designated correct on vertical-sample trials and a green-comparison choice was designated correct on horizontal-sample trials. The remaining birds had the opposite assignments. More importantly, the groups differed in the way in which the outcomes for correct choice were scheduled. For Group Nondifferential, each outcome was scheduled to occur with a probability of .5 on all trials. Thus, both the samples and the correct hue-comparison choices were followed by food and no food with nearly equal frequency over sessions. By contrast, for Group Differential, one outcome was scheduled for correct choices on vertical-sample trials and the other was scheduled for correct choices on horizontal-sample trials. Half of the differential birds received food on vertical-sample trials and no food on horizontal-sample trials; the remaining birds had the opposite assignments. Likewise, half of the differential birds received food following a correct red-comparison choice and no food following a correct green-comparison choice, with the other half experiencing the opposite contingencies. The choice-outcome contingencies for each Group Differential bird, however, were consistent with the hue-outcome contingencies in the prior pretraining phase.

All birds were trained on their respective tasks with a 0 -sec delay between sample offset and comparison onset until $90 \%$ or more correct choices (not including the correction trials) occurred for fjve of six consecutive sessions. One bird in the nondifferential group was dropped from the study after failing to reach this acquisition criterion in 50 sessions. For all other birds, once the criterion was reached, 15 additional training sessions were given during which $0-, 1$-, 2-, and 4-sec delay intervals separated sample offset from comparison onset in each session. In these mixed-delay sessions, each interval occurred equally often on all four trial types.

Form-choice pretraining. Following completion of mixeddelay training, the birds in both groups received differential outcome training with two new side-key stimuli, the triangle and the dot. Each 60-trial session was identical to those run during the earlier, hue-pretraining sessions except for the stimuli appearing singly on the left and right keys and for the fact that food always followed the offset of one stimulus and no food always followed the offset of the other stimulus for all birds. These differential form outcome relations were balanced across the birds in each group. The birds received a minimum of five pretraining sessions with the triangle and dot stimuli. Two birds in Group Nondifferential received an additional two and five sessions, respectively, to ensure that they clearly discriminated the food versus no-food contingencies associated with the triangle and dot prior to the transfer test.

Matching-to-sample testing. In the final experimental phase, the triangle and dot replaced red and green as comparison choices following the vertical and horizontal line samples in matching-tosample. The 10 test sessions were run with mixed delays $(0,1,2$, and $4 \mathrm{sec}$ ) and in the same fashion as previously described, except for (1) the change from hue to form comparison choices and (2) the implementation of differential outcome contingencies for all birds, thus creating identical test conditions for both groups.

For Group Differential, the form choices were substituted for the hue choices such that the form stimulus that had been associated with food in the preceding pretraining phase replaced the hue comparison that had yielded food when correctly pecked during matchingto-sample. Likewise, the form stimulus that had been associated with no food during pretraining replaced the hue comparison that had yielded the no-food outcome in matching-to-sample. The resulting sample-comparison-outcome contingencies were reproduced across the birds in Group Nondifferential (minus the 1 bird that had been dropped from the experiment for failing to meet the acquisition criterion).

Also, between the completion of triangle-dot pretraining and the start of testing, each bird received between one and four "refresher" sessions on its mixed-delay matching-to-sample training task to ensure that baseline matching performances were intact.

\section{Statistical Analyses}

The results of all overall and post hoc $F$ tests reported in this paper were evaluated against the tabled $F$ values reported in Rodger (1975a). These values set Type I error rate (.05 in all of the analyses) on a per-decision, as opposed to an experiment-wise, basis.

\section{Results and Discussion}

\section{Pretraining}

By the end of initial (hue) pretraining, the differential birds regularly and consistently pecked the hue that immediately yielded food when pecked but mostly refrained from pecking the hue that yielded no food. By contrast, the nondifferential birds responded to red and green with roughly equal frequency and rapidity. The left side of Table 2 illustrates these differences in terms of the number of trials out of 30 that each hue was pecked and the latency with which each was pecked (no peck $=5,000 \mathrm{msec}$ ) for each group. The average latencies were computed by calculating the median latency for each hue from each bird's last pretraining session and then averaging the medians across birds. 


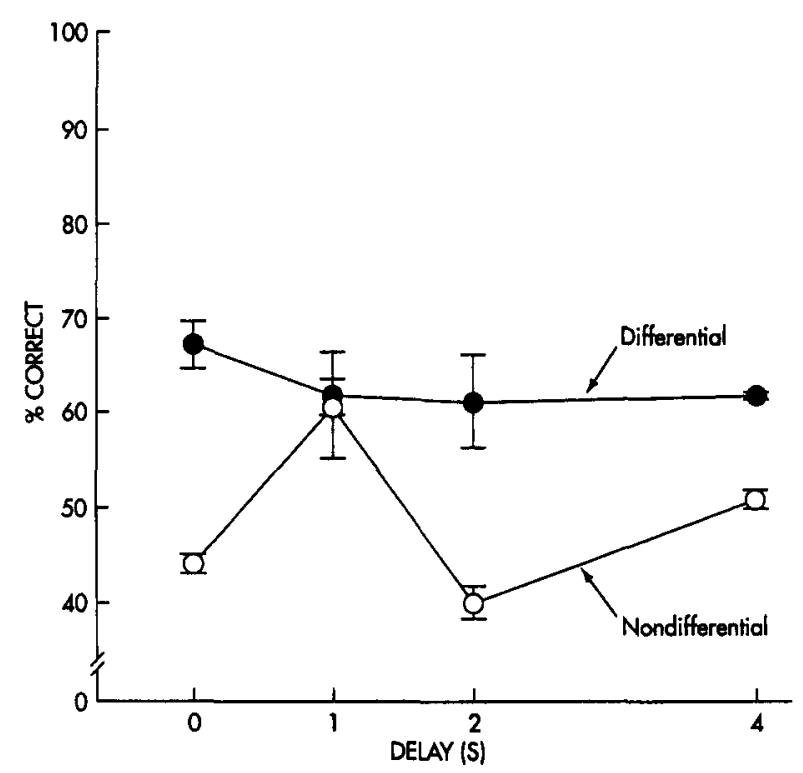

Figure 1. Percentage of correct choice responses for each group by delay on the first transfer test session in Experiment $1 \mathrm{~A}$.

In the form-pretraining phase that followed matchingto-sample training and preceded the transfer test, the triangle and dot were differentially associated with food or no food for all birds. As shown in the right half of Table 2, differential responding to the forms developed in both groups: The birds quickly and consistently pecked the form followed by food and seldom pecked the form followed by no food.

\section{Matching-to-Sample Training}

A differential outcome effect was apparent during matching-to-sample acquisition. Specifically, Group Differential reached criterion levels of accuracy in fewer training sessions (5.0) than Group Nondifferential (21.7) $[F(1,5)=31.89]$. By the end of acquisition, however, performances were comparable in the two groups: Matching accuracies for the last five acquisition sessions were $95.0 \%$ versus $94.9 \%$ correct, respectively, for Groups Differential and Nondifferential $[F(1,5)=0.01]$. When the mixed-delay procedure was then introduced, however, performance differences reemerged. In particular, accuracy was higher overall and was less disrupted by long delays in Group Differential than in Group Nondifferential. Over the last five mixed-delay sessions, the percentages of correct choices on the 0-, 1-, 2-, and 4-sec-delay trials were $96.5 \%, 97.0 \%, 95.5 \%$, and $95.2 \%$, respectively, in Group Differential versus $85.3 \%, 68.7 \%, 74.0 \%$, and $64.3 \%$, respectively, in Group Nondifferential. An analysis of variance (ANOVA) on these data showed significant effects of group $[F(1,5)=23.24]$, delay $[F(3,15)=$ $5.38]$, and group $\times$ delay interaction $[F(3,15)=4.74]$. On the mixed-delay refresher session immediately preceding the transfer test, each group's performance closely resembled the accuracies listed above.

\section{Transfer}

Figure 1 shows matching accuracy by delay for each group on the first test session in which the forms replaced the hues as comparison alternatives. Group Differential matched above the level expected by chance $(50 \%)$ at every delay and was more accurate than Group Nondifferential, whose performance across delays was variable but, on average, close to chance (viz, $50.4 \%$ correct). An ANOVA confirmed that Group Differential was more accurate overall in choosing between the form alternatives than was Group Nondifferential $[F(1,5)=31.75]$. No other effects were significant $[F \mathrm{~s}(3,15)<1.40]$.

Performances over the first 20 test trials were analyzed to assess how soon the between-group differences shown in Figure 1 appeared. Collapsed across delays, matching accuracy for these 20 trials averaged $56.2 \%$ in Group Differential versus $46.7 \%$ in Group Nondifferential. This approximately $10 \%$ accuracy difference approached but did not reach conventional levels of statistical significance $[F(1,5)=4.24]$. Thus, the between-group effect depicted in Figure 1 developed during the first test session. Moreover, in subsequent test sessions, Group Differential achieved successively higher levels of matching accuracy sooner than Group Nondifferential did (data not shown).

These results show that transfer of differential outcome matching-to-sample to new choices can be obtained when those new alternatives are trained outside of the matching context. Previous studies in the matching literature have demonstrated transfer across sample stimuli (e.g., Peterson, 1984; Urcuioli, 1990; Urcuioli \& DeMarse, 1996) or across conditions that could be interpreted as such (Edwards et al., 1982). Thus, the present findings contribute to the existing literature by demonstrating that pigeons' differential outcome performances will transfer to new comparison responses in a manner that cannot be interpreted as a sample substitution effect. In one sense, this is not surprising, given Colwill and Rescorla's (1988, Experiment 1) analogous findings in a free-operant discrimination.

The present data are also theoretically important because they indicate that transfer of differential outcome performances can occur via a mechanism different from that envisioned by two-process theory (Trapold, 1970; see also Honig et al., 1984; Peterson, 1984; Urcuioli \& DeMarse, 1996). According to this theory, transfer is mediated by differential outcome expectancies that have been conditioned to the nominal discriminative stimuli. But since there were no explicit discriminative (i.e., sample) stimuli preceding the dot and triangle responses (and their consequent outcomes) during off-baseline training, it can be reasonably argued that discriminative control over those responses by differential expectancies could not have developed because there were no stimuli to which those expectancies could be conditioned. Without such discriminative control, two-process theory predicts that the samples would be unable to selectively cue one form response over the other in testing.

Nonetheless, the observed transfer results are not entirely compelling. First, although the groups did differ 
significantly in their first-session performances, the effect was not clearly apparent from the outset of that test. This raises the possibility that Group Differential may have simply learned the test contingencies faster by virtue of their prior differential outcome experience. In other words, perhaps the observed between-group differences are not specific to the responses trained off baseline. Second, the interpretation of those differences is clouded by the fact that the groups differed in their mixeddelay baseline performances. Although this will not explain the level of accuracy in Group Differential on its first test session, pretest performance differences make it impossible to pinpoint the source(s) of the betweengroup effect. Experiment 1B, then, was designed to avoid these complications.

\section{EXPERIMENT 1B}

Like Experiment $1 \mathrm{~A}$, the new comparison responses appearing during transfer in this experiment were learned off baseline. Unlike Experiment $1 \mathrm{~A}$, differential outcome matching served as the baseline task for all birds, thus negating the possibility that any performance differences in transfer could be due to the type of outcome contingencies experienced in training. Transfer in $\mathrm{Ex}_{\mathrm{X}}$ periment $1 \mathrm{~B}$ was evaluated by comparing accuracy when each new choice had the same outcome association as the sample to which it was to be matched versus when those choices had the opposite outcome associations. If the bidirectional hypothesis is correct, then performances in the former (outcome-consistent) test condition should be more accurate than in the latter (outcome-inconsistent) test condition.

\section{Method}

\section{Subjects and Apparatus}

The 7 subjects that completed Experiment 1 A participated in Experiment $1 B$. Two of the original Group Differential birds were randomly assigned to the outcome-consistent condition and 2 to the outcome-inconsistent condition. Of the 3 former Group Nondifferential birds, 2 were randomly assigned to the outcome-consistent condition and the remaining $l$ to the outcome-inconsistent condition. The apparatus was the same as that used in Experiment 1A.

\section{Procedure}

The differential outcome matching task used during transfer in Experiment $1 \mathrm{~A}$ served as the baseline for this experiment. Because all birds were matching at criterion levels of accuracy on this linesample, form-choice task at the end of testing in Experiment $1 \mathrm{~A}$, Experiment $1 \mathrm{~B}$ formally began by pretraining them on a new set of response alternatives. This occurred $1-3$ weeks after each bird had completed Experiment $1 \mathrm{~A}$ and was preceded by one or two refresher sessions on its baseline matching task (i.e., its transfer task in Experiment 1A).

Hue-choice pretraining. Each bird received three (and, in one case, four) 60-trial pretraining sessions during which blue and yellow hues appeared singly on the left and right side keys. One hue was always followed by food and the other by no food, with the particular hue-outcome relations balanced across birds. Each outcome occurred immediately upon pecking the hue or automatically after
$5 \mathrm{sec}$. All other details of these pretraining sessions were identical to those described in Experiment $1 \mathrm{~A}$.

Following completion of pretraining, each bird again received one or two refresher sessions on mixed-delay, differential outcome matching-to-sample with the line samples and form comparisons. The refreshers were given to ensure accurate baseline matching prior to testing.

Matching-to-sample testing. All birds were then tested for 10 sessions with the blue and yellow choice alternatives replacing the triangle and dot alternatives for line-sample matching. For the 4 Group Consistent birds, the hue associated with food in the preceding pretraining phase replaced the form alternative that had yielded food in the baseline matching task. Likewise, the hue associated with no food in pretraining replaced the form alternative that had yielded no food in the baseline matching task. By contrast, for the 3 Group Inconsistent birds, the hue associated with food replaced the form associated with no food, and vice versa. It is important to note that, for both groups, each line sample still signaled the same outcome (food or no food) that it had in the baseline matching task. What this meant was that, in the test phase of this experiment, each correct hue choice continued to produce the same outcome that it had in the pretraining phase for Group Consistent but now produced the other outcome for Group Inconsistent.

All other details of the test procedure (including the mixed delays) were the same as those described for transfer in Experiment $1 \mathrm{~A}$.

\section{Results and Discussion}

\section{Baseline and Pretraining Performances}

The birds assigned to Group Consistent and to Group Inconsistent performed comparably at the end of their transfer test in Experiment 1A. An ANOVA on the lastsession performances confirmed that there were no between-group differences $(F \mathrm{~S}<1.62)$. Similarly, the two groups performed comparably on the refresher session preceding the current transfer test. Matching accuracies for Group Consistent were 95.0\%, 96.2\%, 97.5\%, and $97.5 \%$ across the four delays, whereas the matching accuracy for Group Inconsistent was $96.7 \%$ for all four delays $(F \mathrm{~s}<0.12)$.

Moreover, all birds responded differentially to blue and yellow by the end of the pretraining phase. The numbers of pecks (out of 30 ) to the food-associated and nofood-associated hues were 30.0 and 0.5 , respectively, for Group Consistent, and 29.3 and 0.7 , respectively, for Group Inconsistent. The average latencies to peck these hues were 858 and 5,000 msec, respectively, for Group Consistent, and 985 and $5,000 \mathrm{msec}$, respectively, for Group Inconsistent.

\section{Transfer}

Figure 2 shows each group's performance on the first test session. Matching accuracies in Group Consistent were well above chance levels at all four delays, whereas accuracies in Group Inconsistent were at or just slightly above chance. An ANOVA showed that only the overall between-group difference was significant $[F(1,5)=7.34]$.

The difference between Group Consistent and Group Inconsistent appeared very early in testing. For instance, matching accuracy for the first 20 test trials (averaged 


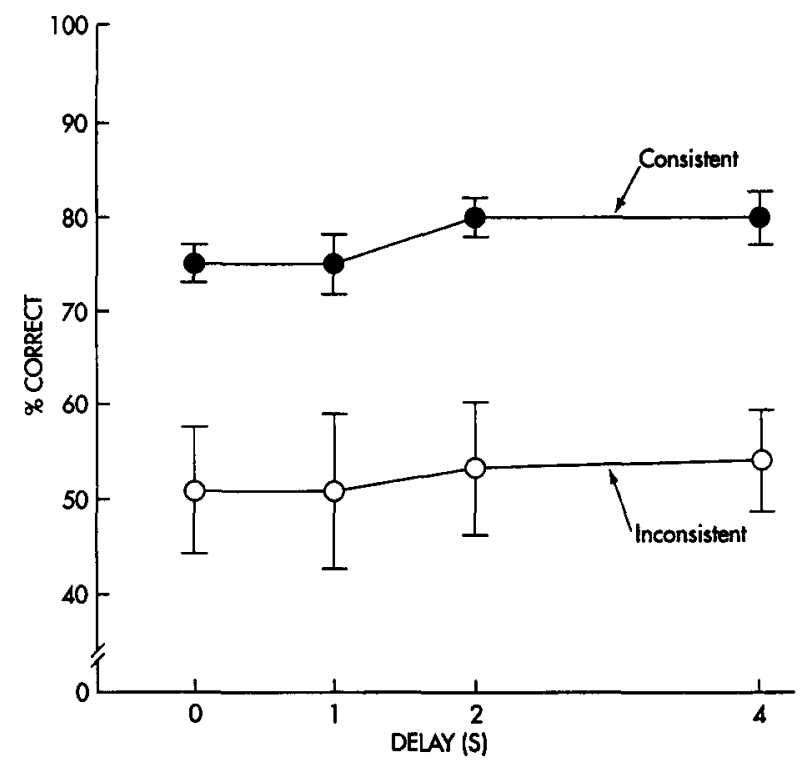

Figure 2. Percentage of correct choice responses for each group by delay on the first transfer test session in Experiment $1 \mathrm{~B}$.

over delays) equaled $65 \%$ correct in Group Consistent and $41.7 \%$ correct in Group Inconsistent $[F(1,15)=17.50]$. These initial-trial data are also noteworthy because they indicate that replacing the form choices in the baseline task with hue choices associated with the opposite outcomes yielded accuracies below the level expected by chance.

Not surprisingly, given these first-session differences, Group Consistent reached $90 \%$ or better accuracy in transfer sooner than Group Inconsistent (data not shown). An ANOVA averaged over delays and over the 10 test sessions revealed a significant effect of group $[F(1,5)=32.78]$, session $[F(9,45)=20.07]$, and group $\times$ session interaction $[F(9,45)=3.25]$.

These data, then, nicely confirm the findings of Experiment $1 \mathrm{~A}$. More importantly, the present results are not subject to the possible alternative interpretations mentioned earlier. First, since the baseline matching task involved differential outcomes for both groups, the differences in their performances during testing cannot be attributed to nonspecific transfer arising from the general nature of their baseline task. Second, prior to testing, the groups did not differ in accuracy on their baseline tasks, so their divergence in testing obviously cannot be explained in that fashion.

One other point is worth noting. Although the blue and yellow hue choices used as substitutes for the forms in testing may have resembled the red and green hue choices used during training in Experiment 1 $\mathrm{A}$, the assignment of birds to the two test conditions in this experiment balanced this potential factor across those conditions. Consequently, stimulus generalization between sets of comparison hues likewise cannot explain the between-group effect seen here.

Thus, it appears that the "new" choices that the birds made in testing reflected the correspondence between the outcomes previously associated with those responses and the outcomes associated with the samples. Specifically, the birds preferentially chose the comparison that shared the same outcome as the line sample preceding it. This was especially obvious in Group Consistent, where such preference led to very high levels of choice accuracy. It was also briefly apparent in Group Inconsistent, which exhibited below-chance levels of accuracy on the initial test trials. This latter effect quickly dissipated, however, since the preferred choice on these early trials was always nonreinforced. Nevertheless, this group's accuracy in testing was far below that shown by Group Consistent, as predicted by the bidirectional hypothesis.

\section{EXPERIMENT 2}

Experiment 2 was an attempt at a systematic replication of Experiments $1 \mathrm{~A}$ and $1 \mathrm{~B}$ under conditions in which the new comparison responses were trained on baseline (i.e., within a matching task) instead of off baseline. The latter procedure, in which each (future) choice alternative was presented singly to the bird, is unlike what transpires in the transfer test where the bird must choose between two simultaneously presented alternatives. Although this did not prohibit transfer of matching to new comparisons in Experiments $1 \mathrm{~A}$ and 1B, it may have yielded some generalization decrement.

As mentioned previously, however, on-baseline training has the potential to create interpretive problems. Specifically, if the matching task in which the new choice-outcome relations are learned permits the development of differential outcome expectancies to the samples (Edwards et al., 1982; see also Table 1), those samplespecific expectancies can then acquire discriminative control over the new choices. If so, transfer of those choices to other samples associated with the same outcomes can be interpreted in two-process terms. To avoid this situation, the new comparison responses (and their differential outcome associations) in Experiment 2 were learned in a task in which (1) each sample stimulus was associated with more than one correct comparison choice (i.e., one-to-many matching; see, e.g., DeMarse \& Urcuioli, 1993; Santi \& Roberts, 1985; Urcuioli, Zentall, \& DeMarse, 1995), (2) each correct response in a pair of choice alternatives yielded a different outcome, and (3) each sample was followed equally often by each outcome. In short, the samples alone did not signal which outcome was scheduled on any given trial. Consequently, they could not by themselves give rise to differential outcome expectancies. By precluding expectancy mediation in this manner, we could again ask whether or not the new responses would transfer to other samples that were differentially associated with the same outcomes.

\section{Method}

\section{Subjects and Apparatus}

Twelve experimentally naive White Carneaux pigeons obtained from the Palmetto Pigeon Plant (Sumter, SC) were used in this experiment. These retired breeders were maintained in the same fashion 
Table 3

Procedure for Experiment 2

\begin{tabular}{crc}
\hline \multicolumn{2}{c}{ Matching-to-Sample Training } & \\
\cline { 1 - 2 } Phase 1 & Phase 2 & Testing \\
\hline & Group Same & \\
$\mathrm{S} 1 \rightarrow \mathrm{R} 1(\mathrm{O} 1)$ & $\mathrm{S} 3 \rightarrow \mathrm{R} 3(\mathrm{O} 1)$ & $\mathrm{S} 1 \rightarrow \mathrm{R} 3(\mathrm{O} 1)$ \\
$\mathrm{S} 2 \rightarrow \mathrm{R} 2(\mathrm{O} 2)$ & $\mathrm{S} 4 \rightarrow \mathrm{R} 4(\mathrm{O} 2)$ & $\mathrm{S} 2 \rightarrow \mathrm{R} 4(\mathrm{O} 2)$ \\
& $\mathrm{S} 3 \rightarrow \mathrm{R} 5(\mathrm{O} 2)$ & $\mathrm{S} 1 \rightarrow \mathrm{R} 6(\mathrm{O} 1)$ \\
& $\mathrm{S} 4 \rightarrow \mathrm{R} 6(\mathrm{O} 1)$ & $\mathrm{S} 2 \rightarrow \mathrm{R} 5(\mathrm{O} 2)$ \\
& Group Reversed & \\
$\mathrm{S} 1 \rightarrow \mathrm{R} 1(\mathrm{O} 1)$ & $\mathrm{S} 3 \rightarrow \mathrm{R} 3(\mathrm{O} 1)$ & $\mathrm{S} 1 \rightarrow \mathrm{R} 4(\mathrm{O} 1)$ \\
$\mathrm{S} 2 \rightarrow \mathrm{R} 2(\mathrm{O} 2)$ & $\mathrm{S} 4 \rightarrow \mathrm{R} 4(\mathrm{O} 2)$ & $\mathrm{S} 2 \rightarrow \mathrm{R} 3(\mathrm{O} 2)$ \\
& $\mathrm{S} 3 \rightarrow \mathrm{R} 5(\mathrm{O} 2)$ & $\mathrm{S} 1 \rightarrow \mathrm{R} 5(\mathrm{O} 1)$ \\
& $\mathrm{S} 4 \rightarrow \mathrm{R} 6(\mathrm{O} 1)$ & $\mathrm{S} 2 \rightarrow \mathrm{R} 6(\mathrm{O} 2)$ \\
& $\mathrm{Group}$ Nondifferential & \\
$\mathrm{S} 1 \rightarrow \mathrm{R} 1(\mathrm{O} 1 / \mathrm{O} 2)$ & $\mathrm{S} 3 \rightarrow \mathrm{R} 3(\mathrm{O} 1)$ & $\mathrm{S} 1 \rightarrow \mathrm{R} 3(\mathrm{O} 1)$ \\
$\mathrm{S} 2 \rightarrow \mathrm{R} 2(\mathrm{O} 1 / \mathrm{O} 2)$ & $\mathrm{S} 4 \rightarrow \mathrm{R} 4(\mathrm{O} 2)$ & $\mathrm{S} 2 \rightarrow \mathrm{R} 4(\mathrm{O} 2)$ \\
& $\mathrm{S} 3 \rightarrow \mathrm{R} 5(\mathrm{O} 2)$ & $\mathrm{S} 1 \rightarrow \mathrm{R} 6(\mathrm{O} 1)$ \\
& $\mathrm{S} 4 \rightarrow \mathrm{R} 6(\mathrm{O} 1)$ & $\mathrm{S} 2 \rightarrow \mathrm{R} 5(\mathrm{O} 2)$ \\
\hline
\end{tabular}

Note-S1-S4 = sample stimuli. R1-R6 = comparison choice responses. $\mathrm{O} 1$ and $\mathrm{O} 2$ represent the food and no-food outcomes, respectively. Counterbalancing of trial types with outcomes is not shown.

as the birds in Experiments $1 \mathrm{~A}$ and $\mathrm{IB}$. The 12 birds were grouped into sets of 3 on the basis of comparable body weights, and 1 from each set was then randomly assigned to one of the three groups described below.

Two BRS/LVE (Laurel, MD) three-key pigeon chambers, whose interior specifications were identical to those previously described, were used for this experiment. Equal numbers of birds from each group were run in each chamber. For this experiment, the inline stimulus projector behind the center key was equipped to project a large white dot on a black background, and white, blue, and yellow homogeneous fields (BRS/LVE Pattern No. 692). The projectors behind each side key could project red and green hues, three white vertical and three white horizontal lines on a black background, three small white dots oriented $+45^{\circ}$ from vertical ("angled dots"), and a pattern of four small white dots ("corner dots") obtained by simultaneously illuminating three vertically oriented dots and three horizontally oriented dots and covering the center dot of each set on the photographic film (Pattern No. 692) with black electrical tape. A single Zenith 286 microcomputer controlled the stimuli and recorded the responses in both experimental chambers.

\section{Procedure}

Preliminary training. Preliminary training to eat from a lit food hopper and to peck lit response keys proceeded much like that in Experiment 1A. Over five sessions, each bird learned to peck the dot and the white field, and the blue and yellow hues, on the center key, and vertical and horizontal lines, red and green hues, and the angled and corner dots on the side keys. The order of center-key and side-key training and the structure of these preliminary training sessions were similar to those in Experiment $1 \mathrm{~A}$.

Sample pretraining. Next, the birds were given five pretraining sessions with the stimuli that would later serve as samples in the matching tasks. All trials in these sessions began with the appearance of the inverted white triangle as a trial-ready stimulus on the center key. A single peck to the triangle turned it off and, $500 \mathrm{msec}$ later, produced either the dot or the white stimulus (first three sessions) or the blue or yellow hue (last two sessions) on the center key. Each stimulus remained on for $5 \mathrm{sec}$, after which it was turned off independently of responding and was followed immediately by food or no food. The probability that food (or no food) would occur following stimulus offset was .5 on all trials (i.e., outcomes were nondifferential with respect to dot and white and to blue and yellow).
Successive trials in these 60 -trial sessions were separated by a 10 sec ITI, with the houselight off during the first $9 \mathrm{sec}$. The order of stimulus presentation was randomized, with the constraint that each stimulus appear equally often in a session.

Phase 1 matching-to-sample. After completing pretraining, all birds were trained on 0-delay matching-to-sample with blue and yellow samples and vertical and horizontal comparisons, as shown schematically in the left column of Table 3 . The inverted white triangle again served as a trial-ready stimulus for each of the 80 matching trials per session. For all birds, a vertical choice (R1) was correct following the blue sample (S1), and a horizontal choice (R2) was correct following the yellow sample (S2). Details regarding trial sequencing, reinforcement duration, the correction procedure for incorrect choices, the performance criterion, and so on were identical to those described for the matching-to-sample tasks in Experiments $1 \mathrm{~A}$ and $1 \mathrm{~B}$. The only notable difference was that each sample appeared for $5 \mathrm{sec}$ (rather than for $3 \mathrm{sec}$ ).

For two groups (Group Same and Group Reversed), the matching task involved differential (food vs. no food) outcomes. For half of the birds in these two groups, food (O1) followed the correct vertical choice (R1) on blue- sample (S1) trials and no food (O2) followed the correct horizontal choice (R2) on yellow-sample (S2) trials. The remaining birds had the opposite outcome assignments. For Group Nondifferential, all correct choices produced food and no food with equal probability. Each bird was trained on its respective task until it matched at or above $90 \%$ accuracy for five of six consecutive sessions.

Phase 2 one-to-many matching-to-sample. Next, all birds were trained on one-to-many matching-to-sample with dot and white samples ( $\mathrm{S} 3$ and $\mathrm{S} 4$ ), red versus green (R3 and R4) and angled versus corner dots (R5 and R6) choice alternatives, and differential (food vs. no food) outcomes (O1 and $\mathrm{O} 2$ ). Each one-to-many trial began with the trial-ready stimulus, which, when pecked, turned off and was followed $500 \mathrm{msec}$ later by a dot or white center-key sample. The sample stimulus went off automatically after $5 \mathrm{sec}$ and was followed either by red and green hues or by the angled and corner dots on the side keys. A single peck to either choice alternative turned both off and produced either food or no food if the choice was correct or turned off the houselight if the choice was incorrect. For all birds, pecking the red hue (R3) or the angled dots (R5), whichever was available, was correct on dot-sample (S3) trials, whereas pecking the green hue (R4) or the corner dots (R6), whichever was available, was correct on white-sample (S4) trials. The alternative choices were incorrect and, along with turning off the houselight, caused the same trial to be repeated after the usual 10 -sec ITI. For half of the birds in each group, food (O1) followed correct red and corner-dot choices, and no food (O2) followed correct green and angled-dot choices; the remaining birds had the opposite outcome assignments. These contingencies, depicted in the middle column of Table 3, ensured that the choice responses for each set of alternatives were associated with different outcomes and, just as importantly, that those outcomes occurred with equal frequency following each sample stimulus.

Presentation of the eight possible trial types $(2$ samples $\times 2$ sets of choice alternatives $\times 2$ left-right configurations of each choice set) was randomized in each 96-trial session, with the constraints that no trial type occur more than three times in a row and that all trial types occur equally often. Each bird was trained on one-tomany matching until it achieved an overall accuracy level of $90 \%$ correct or better for five of six consecutive sessions and at least $87.5 \%$ correct choices with each set of comparison alternatives. At that point, the bird was given refresher training on its Phase 1 task until it matched at $90 \%$ correct or better for a single session.

Testing. Following the last refresher session, a single test session was scheduled in which the two sets of comparison choice responses trained in the one-to-many task were substituted for the choices in Phase 1 matching, as shown in the right column of Table 3. Half of the 96 test trials involved the blue sample (S1) from Phase 1, and the other half involved the yellow sample (S2). After 
Table 4

Average Latencies to Correct Comparison Choice (in Milliseconds) for Each Group in Experiment 2 Over its Last Five One-to-Many (Phase 2) Training Sessions

\begin{tabular}{lrcc}
\hline & \multicolumn{3}{c}{ Group } \\
\cline { 2 - 4 } Comparison-Outcome & Same & Reversed & Nondifferential \\
\hline Hue-food & 815 & 924 & 1,055 \\
Hue-no-food & 6,904 & 9,652 & 7,896 \\
Form-food & 718 & 886 & 981 \\
Form-no-food & 7,710 & 8,740 & 7,152 \\
\hline
\end{tabular}

a 5-sec sample presentation, one of the two "new" sets of comparison alternatives (red and green, or angled and corner dots) appeared on the left and right side keys. For Group Same, a single peck to the comparison that, in one-to-many matching, had been followed by the same outcome as the Phase 1 sample was reinforced by that outcome. For Group Reversed, the correct choice on each trial was to the alternative that had been associated with the opposite outcome vis-à-vis the $\mathrm{S} 1$ and $\mathrm{S} 2$ samples. Although it appears from Table 3 that these two groups were tested on different matching tasks, counterbalancing of the outcomes with the trial types in each training phase guaranteed that each set of matching contingencies in testing was equally represented across Groups Same and $\mathrm{Re}-$ versed. The test contingencies for the 4 birds in Group Nondifferential matched those in Group Same. Thus, the $\mathrm{R}-\mathrm{O}$ associations in the nondifferential controls were identical to those in Phase 2 training. However, since their $\mathrm{S} 1$ and $\mathrm{S} 2$ samples did not originally have differential outcome associations (cf. Phase 1), the test performances in this group allowed us to assess the degree to which transfer (if any) in Group Same could be attributable solely to maintenance of the Phase $2 \mathrm{R}-\mathrm{O}$ associations.

Note also that the one-to-many task used in testing differed from the one used in Phase 2 training, because each sample stimulus ( $\mathrm{S} 1$ and S2) was now associated with a different outcome, as was the case for these samples during Phase 1 training. All other procedural details, however, were identical to those for the Phase 2 one-to-many task.

Following the completion of the first test session, each bird was retrained on its two training tasks in preparation for a second test session identical to the first. The retraining sequence involved refresher training on the one-to-many (Phase 2) task followed by refreshers on Phase 1 matching and, finally, by an additional refresher on one-to-many matching. Each bird was retrained on each task until its performance met criterion levels of accuracy for a single session.

Assuming transfer of matching to new comparison responses, we predicted the following ordering of accuracies during testing: Group Same $>$ Group Nondifferential > Group Reversed.

\section{Training and Refreshers}

Acquisition of Phase 1 matching was significantly more rapid in the two differential outcome groups (Same and Reversed) than in the nondifferential control. For instance, Groups Same and Reversed needed only 5.5 and 6.8 sessions, respectively, to reach $90 \%$ accuracy $[F(2,9)=$ 0.15 ], relative to 13.5 sessions for Group Nondifferential $[F(2,9)=6.89]$. Over the last five acquisition sessions, matching accuracies were very high in all three groups $(97.2 \%, 95.3 \%$, and $93.8 \%$ correct, respectively), although significantly higher in the two differential groups $[F(2,9)=3.47]$.

Despite considerable variability across subjects, acquisition of the common one-to-many task in Phase 2 was similar across groups. The average numbers of sessions to criterion for Groups Same, Reversed, and Nondifferential were $14.8,19.8$, and 22.2 , respectively. There was no significant between-group difference in this measure $[F(2,9)=0.77]$, nor in matching accuracies averaged over the last five Phase 2 sessions $(94.5 \%, 94.3 \%$, and $94.5 \%$ correct, respectively) $[F(2,9)=0.05]$.

Table 4 shows the average latencies to correct comparison choice in each group over its last five Phase 2 training sessions. The differential $\mathrm{R}-\mathrm{O}$ relations had a clear and pronounced effect on choice latencies. Specifically, correct choices generally occurred in less than $1 \mathrm{sec}$ when reinforced by food, whereas latencies averaged $7 \mathrm{sec}$ or longer when followed by no food. An ANOVA showed that, averaged across groups, the choice latencies on food trials were significantly shorter than on no-food trials $[F(1,11)=156.21]$

On the Phase 1 refresher session immediately preceding the first transfer test, matching accuracies were uniformly high in all three groups $(95.6 \%, 92.2 \%$, and $94.4 \%$ correct for Groups Same, Reversed, and Nondifferential, respectively) and did not differ significantly between them $[F(2,9)=1.63]$. Similarly, the groups did not differ significantly in accuracy on the one-to-many refresher session immediately preceding the second test $(95.3 \%$, $96.4 \%$, and $94.8 \%$, respectively) $[F(2,9)=0.62]$.

\section{Testing}

Figure 3 shows each group's performance on the two transfer tests. On the first test day, Group Same matched above the level expected by chance $(66.7 \%)$, whereas both Group Reversed and Group Nondifferential performed close to chance ( $46.7 \%$ and $51.3 \%$ correct, respectively). An ANOVA confirmed the overall between-group difference $[F(2,9)=7.19]$. Post hoc contrasts on these data showed that Groups Reversed and Nondifferential did not differ from each other $[F(2,9)=0.36]$ but were less accurate in their choices than Group Same $[F(2,9)=6.83]$.

On the second test day, transfer performances in all three groups improved relative to the first test, but the between-group differences remained. Matching accuracy for Group Same was $89.6 \%$ correct on the second test, whereas matching accuracies for Groups Reversed and Nondifferential were $58.3 \%$ and $71.1 \%$ correct, respectively. These results show a clear ordering in accuracy across groups: Group Same being the most accurate, Group Reversed the least, and Group Nondifferential intermediate. Post hoc contrasts confirmed this pattern (see Rodger, 1975b, Equation 23) by showing that Group Same was more accurate on the second test day than was Group Reversed $[F(2,9)=41.19]$ and that the average of their performances was not significantly different from that exhibited by Group Nondifferential $[F(2,9)=0.46]$.

\section{Discussion}

Experiment 2 showed that differential outcome matching would transfer to new comparison responses trained on baseline in a matching task in which the samples alone did not signal which outcome was scheduled for any 


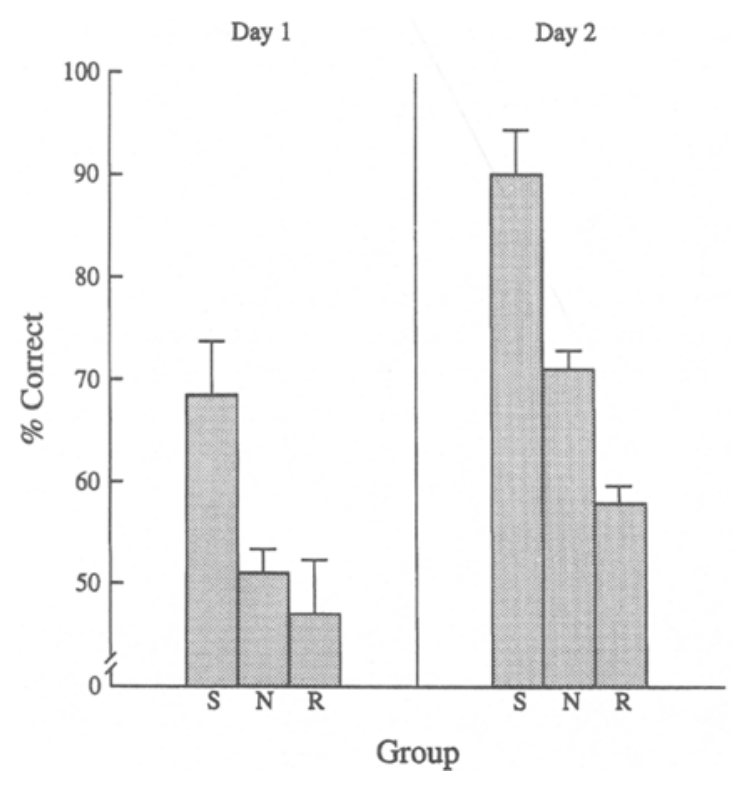

Figure 3. Percentage of correct choice responses for each group in Experiment 2 on its first and second transfer tests. $S$, $\mathbf{N}$, and $\mathbf{R}$ represent Groups Same, Nondifferential, and $R e-$ versed, respectively.

given trial. The latter feature of the on-baseline procedure rules out the possibility that the observed transfer can be reinterpreted as a sample-substitution effect. In other words, unlike the findings of previous studies (e.g., Edwards et al., 1982), the present data are not readily amenable to a two-process account that posits mediation of the new choices by sample-specific expectancies (Peterson, 1984; Trapold, 1970). Even though differential outcome expectancies should have arisen from the samples in testing in Groups Same and Reversed, those expectancies would not have been previously established as discriminative cues for the transfer choice responses.

The overall pattern of accuracy in the second transfer test session clearly confirmed our predictions, but the pattern seen in the first test only partially confirmed them. Specifically, in the first test session, Group Same matched more accurately than the other two groups, but Group Reversed was not decidedly less accurate than Group Nondifferential (cf. Test Day 1 in Figure 3). The latter prediction was based on the reasoning that Group Reversed should consistently choose the incorrect comparison because their test contingencies reinforced responses to comparisons that had been associated with outcomes opposite of those signaled by the S1 and S2 samples. However, if these birds regularly chose the outcomeconsistent comparison alternative, their choices would be regularly nonreinforced, which, in turn, should diminish the amount of negative transfer observed (e.g., by inducing a simple position or stimulus preference).

Consequently, we examined how accurately the Group Reversed birds matched during the early trials of testing before any substantial extinction might have occurred.
Over the first 32 trials of Test Day 1, matching accuracy in Group Reversed averaged $40.6 \%$ correct, with 2 of the 4 birds choosing correctly on only $34.4 \%$ and $28.1 \%$ of these trials. The corresponding figures for Groups Same and Nondifferential were $68.0 \%$ and $45.3 \%$ correct, respectively. We conducted $t$ tests to evaluate whether any of these figures differed significantly from chance $(50 \%)$ performance. Only the initial-trial performance by Group Same deviated significantly from chance $[t(3)=$ $2.98, p<.05]$. However, the results from Group Reversed were skewed by the performance of 1 bird that matched close to chance throughout its first test session. For the remaining 3 Group Reversed birds, their initial (32-trial) accuracy was significantly below the level expected by chance $(35.4 \%)[t(2)=-3.21, p<.05]$. When the same analyses were conducted on the accuracy scores from the entire session (i.e., those depicted in the left panel of Figure 3), this same pattern of results was obtained.

The second transfer test was not expected to produce below-chance accuracy in Group Reversed, given its exposure to the test contingencies in the first test. However, we expected, and obtained, lower accuracy in this group than in Group Nondifferential. This result, in conjunction with the roughly comparable accuracies shown by these two groups in the first test, shows that the prior differential outcome experience that Group Reversed received with the S1 and S2 samples did not convey any advantage in testing relative to Group Nondifferential. If it had, then, from a generalization decrement standpoint, Group Reversed should have performed more accurately in testing than Group Nondifferential, and this was clearly not the case.

Still, given some ambiguity regarding whether or not Group Reversed truly matched below the level expected by chance during its first test session, its relatively low accuracy during transfer might be dismissed as the consequence of reversing its $\mathrm{R}-\mathrm{O}$ relations from Phase 2 training to testing versus maintaining them in Group Same (cf. the middle and right columns of Table 3). However, if reversal versus maintenance of these relations were the sole source of the performance difference between these two groups, then we would expect Group Nondifferential to match at an accuracy level comparable to that of Group Same because its $\mathrm{R}-\mathrm{O}$ relations were also maintained in the shift from training to testing. Contrary to prediction, however, accuracy in Group Nondifferential during transfer was considerably lower than that in Group Same.

\section{EXPERIMENT 3}

The results obtained so far do not seem explicable by two-process theory. According to this account, transfer of matching to new choices requires that differential outcome expectancies acquire discriminative control over the choices in training. But this control should not have developed either in Experiments $1 \mathrm{~A}$ and $1 \mathrm{~B}$, where there were no samples to which different expectancies could 
be conditioned as the new responses were being learned, or in Experiment 2, where each sample was followed by each outcome equally often.

By contrast, the bidirectional hypothesis (Rescorla, 1992; Rescorla \& Colwill, 1989) readily accounts for the data. For example, it predicts that R3-R6 would substitute for R1 and R2 in Experiment 2 because (1) the members of both the R3-R4 pair and the R5-R6 pair were associated with different outcomes in training and (2) the samples used in testing ( $\mathrm{S} 1$ and S2) had also been associated with those outcomes. Thus, presentation of S1 and S2 in testing should give rise to different outcome representations that could then cue R3 or R4, or R5 or R6, via the backward action of the $\mathrm{R}-\mathrm{O}$ associations.

The bidirectional hypothesis also predicts that substituting the comparison choices from initial training (viz, R1 and R2) into the Phase 2 one-to-many task of Groups Same and Reversed should not yield transfer of performance (cf. Table 3). The reason is that the $\mathrm{S} 3$ and $\mathrm{S} 4$ samples, by virtue of their associations with both outcomes, cannot give rise to the unique outcome representations needed to activate the $\mathrm{R}-\mathrm{O}$ associations involving $\mathrm{R} 1$ and $\mathrm{R} 2$. Thus, the same logic used to derive the two-process prediction of "no transfer" for Experiment 2 can be used to derive the bidirectional prediction of no transfer to $\mathrm{R} 1$ and R2.

On the other hand, a modified version of two-process theory to which we have previously alluded (see Urcuioli \& DeMarse, 1997, p. 181) does predict that R1 and R2 will be correctly matched to S3 and S4. The modification states that when the samples alone do not uniquely signal outcomes (as in one-to-many matching), birds can nonetheless learn to predict outcomes on the basis of a combination of the sample on a given trial with the choice alternatives that follow it. For instance, consider the very different appearance of the pairs of choice alternatives in the one-to-many task of Experiment 2: homogeneous hues on some trials versus small sets of dots ("forms") on other trials. Under these circumstances, birds might learn that the S3 sample plus side-key hues signals food, whereas that sample plus forms signals no food. Conversely, the $\mathrm{S} 4$ sample plus the forms signals food, whereas S4 plus hues signals no food.

This idea can be tested by substituting the vertical and horizontal choice alternatives into the one-to-many task and by making the reasonable assumption that white lines on black backgrounds appear more similar to white dots on black backgrounds than to homogenous colored fields. In other words, given generalization between the lines and forms, each dot choice alternative should be replaceable by a line alternative with the same outcome association. Thus, if the corner dots were followed by food on S3 trials in Phase 2 and a correct vertical choice originally yielded food in Phase 1 , vertical should readily substitute for the corner dots on these trials. Likewise, if the angled dots were followed by no food on S4 trials and a correct horizontal choice had originally yielded no food, horizontal should likewise substitute for the angled dots.
By contrast, replacing the red and green hue choices with the lines would not be expected to have this effect. Indeed, for reasons to be spelled out more fully momentarily, this substitution should yield negative transfer of performance. In essence, the idea is that all test trials would then be of the same general type-namely, consisting of nonhue (i.e., "form") choice alternatives. Thus, the sample-plus-line trials should produce the same expectancies as would the sample-plus-dot trials, and, in order to maintain both the previously trained line-outcome and sample-outcome relations, line choices opposite those cued by the outcome expectancies would have to be reinforced.

\section{Method}

\section{Subjects and Apparatus}

The 12 White Carneaux pigeons used in Experiment 2 served in this experiment. Two birds from each differential outcome group (Same and Reversed) were randomly assigned to Group Pos, and the remaining 2 birds were assigned to Group Neg. The group labels denote the fact that the substitution of the Phase 1 choice responses into the one-to-many task was predicted to produce positive and negative transfer of performance, respectively, to those "new" choice alternatives. The 4 birds from the nondifferential control group in Experiment 2 were assigned to Group Null. For them, the corresponding substitutions were predicted to yield neither positive nor negative deviation from chance performance because the line choices had not been associated with different outcomes in training.

The apparatus was the same as that used in Experiment 2.

\section{Procedure}

Immediately following completion of Experiment 2, each bird received refresher training on its Phase 2 one-to-many matching task (see Table 3) followed by refresher training on Phase 1 matchingto-sample. Refresher sessions on each training task were given until accuracy met or exceeded the performance criterion previously described for a single session. For Phase 2 one-to-many matching, the average number of refresher sessions was 1.5 (range $=1-4$ ); for Phase 1 matching, it was 1.1 sessions (range $=1-2$ ).

Each bird was then tested with the vertical and horizontal choice alternatives ( $\mathrm{R} 1$ and $\mathrm{R} 2$ ) replacing either the hue or the form alternatives in one-to-many matching. In Group Pos, vertical and horizontal were substituted for the corner- and angled-dot forms, whereas in Group Neg, they were substituted for the red and green hues. These substitutions are depicted in the right column of Table 5 . In Group Null (not shown), the lines replaced the forms for 2 birds and the hues for the other 2 birds.

For Groups Pos and Neg, the $\mathrm{R}-\mathrm{O}$ relations established in Phase 1 matching remained the same in testing. In other words, if a correct vertical choice had yielded food in original training and if a correct horizontal choice had yielded no food, the same contingencies were in effect in testing. By contrast, the Group Null birds, which received nondifferential outcome training in Phase 1, now experienced different outcomes following correct vertical and horizontal choices. The switch in outcome contingencies for these birds was done in order to equate their test contingencies with those in Groups Pos and Neg. All birds received 10 days of testing.

\section{Predictions}

Below the training and test schematics for Groups Pos and Neg in Table 5 are the theoretics used to derive the predictions outlined in the introduction. The hypothesized outcome expectancies and the sample-choice compounds from which they presumably arise during Phase 2 and Testing are italicized. 
Table 5

Examples of Matching Contingencies and Theoretics for Groups Pos and Neg in Experiment 3 Training

\begin{tabular}{llc}
\hline \multicolumn{1}{c}{ Phase 1 } & \multicolumn{1}{c}{ Phase 2 } & \multicolumn{1}{c}{ Testing } \\
\hline & \multicolumn{1}{c}{ Group Pos } & \\
$\mathrm{S} 1 \rightarrow \mathrm{V}$ (Food) & $\mathrm{S} 3 \rightarrow \mathrm{R}$ (Food) & $\mathrm{S} 3 \rightarrow \mathrm{R}$ (Food) \\
$\mathrm{S} 2 \rightarrow \mathrm{H}$ (No Fd) & $\mathrm{S} 4 \rightarrow \mathrm{G}$ (No Fd) & $\mathrm{S} 4 \rightarrow \mathrm{G}$ (No Fd) \\
& $\mathrm{S} 3 \rightarrow \mathrm{AD}$ (No Fd) & $\mathrm{S} 3 \rightarrow \mathrm{H}$ (No Fd) \\
& $\mathrm{S} 4 \rightarrow \mathrm{CD}$ (Food) & $\mathrm{S} 4 \rightarrow \mathrm{V}$ (Food) \\
$E_{f} \rightarrow \mathrm{V}$ & $S 3+$ forms $\rightarrow E_{n f}$ & $\mathrm{~S} 3+$ forms $\rightarrow E_{n f} \rightarrow \mathrm{H}$ \\
$E_{n f} \rightarrow \mathrm{H}$ & $S 4+$ forms $\rightarrow E_{f}$ & $S 4+$ forms $\rightarrow E_{f} \rightarrow \mathrm{V}$ \\
& \multicolumn{1}{c}{ Group Neg } & \\
$\mathrm{S} 1 \rightarrow \mathrm{V}$ (Food) & $\mathrm{S} 3 \rightarrow \mathrm{R}$ (Food) & $\mathrm{S} 3 \rightarrow \mathrm{V}$ (Food) \\
$\mathrm{S} 2 \rightarrow \mathrm{H}$ (No Fd) & $\mathrm{S} 4 \rightarrow \mathrm{G}$ (No Fd) & $\mathrm{S} 4 \rightarrow \mathrm{H}$ (No Fd) \\
& $\mathrm{S} 3 \rightarrow \mathrm{AD}$ (No Fd) & $\mathrm{S} 3 \rightarrow \mathrm{AD}$ (No Fd) \\
& $\mathrm{S} 4 \rightarrow \mathrm{CD}$ (Food) & $\mathrm{S} 4 \rightarrow \mathrm{CD}$ (Food) \\
& $S 3+$ forms $\rightarrow E_{n f}$ & $S 3+$ forms $\rightarrow E_{n f} \rightarrow \mathrm{V}$ \\
$E_{f} \rightarrow \mathrm{V}$ & $S 4+$ forms $\rightarrow E_{f}$ & $S 4+$ forms $\rightarrow E_{f} \rightarrow \mathrm{H}$ \\
$E_{n f} \rightarrow \mathrm{H}$ & &
\end{tabular}

Note-S1-S4 = sample stimuli. $\mathrm{V}=$ vertical lines. $\mathrm{H}=$ horizontal lines. $\mathrm{R}=$ red. $\mathrm{G}=$ green. $\mathrm{AD}=$ angled dots. $\mathrm{CD}=$ corner dots. No $\mathrm{Fd}=$ no food. $E_{f}=$ expectancy of food. $E_{n f}=$ expectancy of no food. The hypothesized outcome expectancies and the sample-choice compounds from which they presumably arise during Phase 2 and Testing are italicized.

As a result of Phase 1 training, both groups presumably learned to choose vertical in the presence of an expectancy of food $\left(E_{f}\right)$ and horizontal in the presence of an expectancy of no food $\left(E_{n f}\right)$. During one-to-many training in Phase 2 , both groups presumably learned to expect no food when the form comparisons appeared following the S3 sample, and they learned to expect food when the form comparisons appeared following the $\mathrm{S} 4$ sample. (Not shown are the corresponding expectancies for the hue-comparison trials.) Finally, in testing, we assume that the presentation of the line choices after $\mathrm{S} 3$ and $\mathrm{S} 4$ yields sample-choice compounds similar to those in Phase 2 (i.e., samples + forms). If so, the birds should again expect no food given $\mathrm{S} 3$ plus forms, and they should expect food given S4 plus forms. In Group Pos, this should provide an accurate cue for choosing between the horizontal and vertical alternatives. In other words, for this group, the expectancy-line choice relations are the same as those presumably learned in Phase 1 matching. By contrast, the test contingencies for Group Neg reverse those relations. Now, a vertical choice is correct when a no-food expectancy is present, and a horizontal choice is correct when a food expectancy is present. The contingencies for Group Neg arise because (1) the dot choices continue to appear on half of the trials and are reinforced as in one-to-many training, (2) the line choiceoutcome relations are the same as in Phase 1 training, and (3) to ensure that the samples (S3 and S4) continue to be followed by each outcome equally often, the vertical choice must be correct (and followed by food) on $\mathrm{S} 3$ trials and the horizontal choice must be correct (and followed by no food) on S4 trials. Thus, for Group Neg, the accuracy of choosing between vertical and horizontal in testing should fall below the level expected by chance.

\section{Results}

Matching accuracies on the Phase 1 and Phase 2 refresher sessions were comparable across groups. For example, on the final one-to-many refresher, Groups Pos, $\mathrm{Neg}$, and Null chose correctly on $97.4 \%, 94.5 \%$, and $94.5 \%$ of all trials, respectively $[F(2,9)=1.28]$. The corresponding figures for the final Phase 1 refresher were
$96.2 \%, 97.5 \%$, and $93.4 \%$ correct, respectively, which were likewise not significantly different $[F(2,9)=3.24]$.

Figure 4 shows the first-session test results for each group on the novel line-comparison matching trials. Accuracy on these trials in Group Pos $(75.5 \%)$ was well above the level expected by chance, whereas corresponding accuracy in Group Neg (40.1\%) was below chance. The average performance in Group Null $(63.5 \%)$ was roughly midway between those of the other two groups. An ANOVA on these data showed a significant betweengroup effect $[F(2,9)=12.78]$. Post hoc contrasts confirmed that matching accuracy on the line-comparison test trials was higher in Group Pos than in Group Neg $[F(2,9)=$ 12.36], with Group Null exhibiting an intermediate level of accuracy $[F(2,9)=0.43]$.

Performances during the initial 48 trials of the first test session (not shown) mirrored those shown in Figure 4. Line-comparison accuracies averaged $68.8 \%$ correct in Group Pos (range $=50 \%-83.3 \%$ ), $34.4 \%$ correct in Group Neg (range $=20.8 \%-50 \%$ ), and $58.3 \%$ correct in Group Null (range $=50 \%-66.7 \%$ ). An ANOVA and post hoc contrasts on these data revealed exactly the same pattern as that described above. Of particular interest, however, is the sizable and significant negative transfer shown by Group Neg on these initial test trials (i.e., prior to any substantial extinction of outcome-consistent choices) $[t(3)=$ $-2.51, p<.05]$.

During testing, only one set of the original comparisons was replaced in the one-to-many task. The other, alternate set continued to appear on the remaining trials.

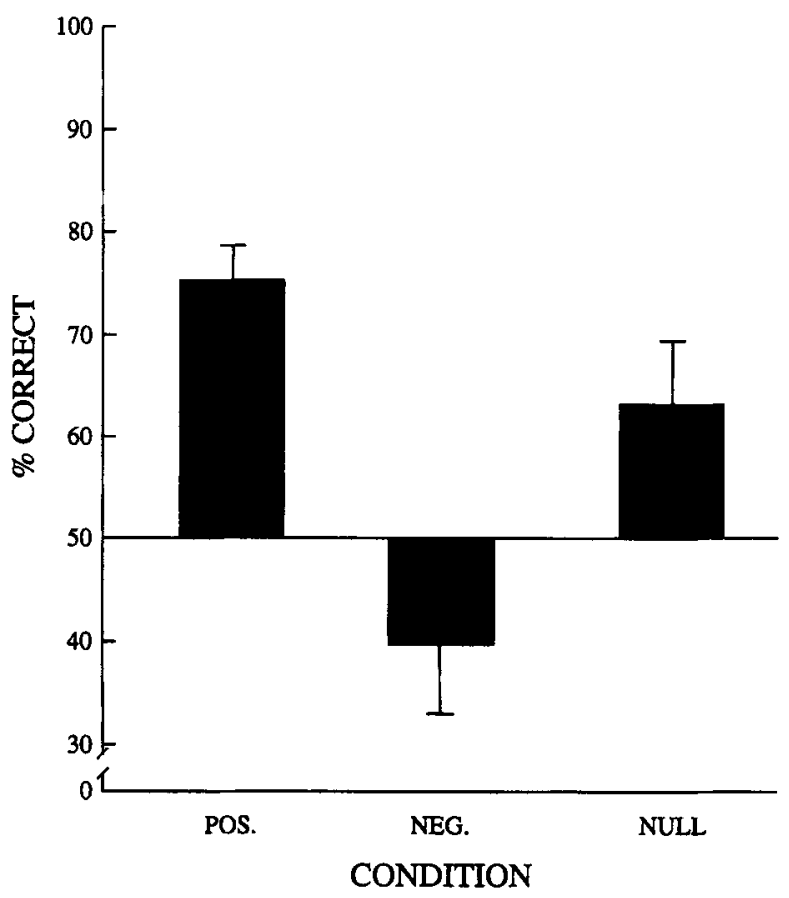

Figure 4. Percentage of correct choice responses on linecomparison test trials for each group on its first transfer test session in Experiment 3. 
In Group Pos, the alternate set involved the red and green choice alternatives; accuracy on these trials averaged $95.3 \%$ correct. In Group Neg, the unchanged alternatives were the angled and corner dots; accuracy on these trials was $77.1 \%$ correct. Finally, the unchanged alternatives were the hues for 2 of the Group Null birds and the forms for the remaining 2. Matching accuracies were $91.7 \%$ and $84.4 \%$ correct, respectively.

\section{Discussion}

Experiment 3 was originally designed to provide another test of the bidirectional hypothesis of differential outcome performance. This hypothesis predicts that choice responses associated with different outcomes in one matching task will not substitute for those in another if the samples in testing do not generate unique outcome representations. Contrary to prediction, transfer of matching did occur under these circumstances.

Experiment 3 also permitted a test of the notion that outcome expectancies might develop from a combination of a sample stimulus plus the choice alternatives that follow it. Assuming that sample-choice compounds can be a source of differential expectancies, then the results support two-process theory. As mentioned previously, the mediation mechanism posited by this theory to account for transfer (Peterson, 1984) requires that differential outcome expectancies occur prior to choice responding and that they exert discriminative control over choice (Urcuioli \& DeMarse, 1996). But the samples appearing in the test phase of this experiment could not, by themselves, have generated differential expectancies because their outcome associations during training were nondifferential. However, if the birds could anticipate different outcomes on seeing which choice alternatives appeared following a given sample, then expectancy mediation would be possible. Our predictions, then, of positive and negative transfer in Groups Pos and Neg, respectively, as derived with the added assumption of generalization between the line choices in testing and the form choices they replaced, were confirmed by the data.

Still, if the two-process account is rescued by assuming that outcome expectancies can develop from samplechoice compounds, then the same latitude should be given to the bidirectional hypothesis. In other words, those compounds should, by similar argument, generate the differential representations needed to activate backward $\mathrm{R}-\mathrm{O}$ associations. Thus, the results of this experiment may not be as theoretically discriminating as they initially appear, given identical modifications to both theories. Nonetheless, the data are important because they demonstrate transfer of matching to new comparisons under conditions in which unembellished versions of each theory predict no transfer.

\section{GENERAL DISCUSSION}

The present study makes both empirical and theoretical contributions to the differential outcome literature. Empirically, Experiments $1 \mathrm{~A}$ and $\mathrm{IB}$ demonstrated transfer of differential outcome matching-to-sample to new comparison responses trained off baseline. This finding complements other results in the literature showing that pigeons will transfer their performances to new sample stimuli trained off baseline (e.g., Peterson, 1984; Urcuioli, 1990; Urcuioli \& DeMarse, 1996). Moreover, the results extend previous findings of transfer to topographically different responses acquired in the absence of explicit $\mathrm{S}^{\mathrm{D}} \mathrm{S}$ (Colwill \& Rescorla, 1988) to topographically similar (if not identical) new responses.

The results of Experiments $1 \mathrm{~A}$ and $1 \mathrm{~B}$ also complement the transfer findings of Edwards et al. (1982). The major difference between studies was that the pigeons in our experiments learned the new comparison $\mathrm{R}-\mathrm{O}$ relations outside of matching-to-sample, whereas the pigeons in Edwards et al.'s study learned them in a matching task. Apparently, then, differential outcome transfer by pigeons occurs independently of whether the new responses are learned on or off baseline. In free-operant paradigms, the same holds true (Colwill \& Rescorla, 1988; Rescorla \& Colwill, 1989, Experiment 4).

Experiment 2 reinforced this latter point. In it, the new $\mathrm{R}-\mathrm{O}$ relations were learned on baseline but in a matching task in which the samples alone were uncorrelated with the different outcomes. This arrangement was believed to preclude the possibility that the target responses would be cued by differential outcome expectancies given that the samples preceding those responses were unreliable signals for the contingent outcomes. The finding that responses acquired in this fashion, like those acquired off baseline in Experiments $1 \mathrm{~A}$ and 1 B, did transfer to other samples with which they shared common outcome associations poses serious problems for twoprocess theory. As mentioned earlier, this theory anticipates transfer if the responses in testing are under discriminative control of differential outcome expectancies (and the samples in testing produce those different expectancies). The responses in this case, however, were acquired in a matching task in which sample-specific expectancy control should not have developed because those samples were uncorrelated with the outcomes.

Theoretically, then, the present study shows that a two-process account that relies solely on the samples (or any other $\mathrm{S}^{\mathrm{D}} \mathrm{s}$ ) to provide the source of transfer-mediating outcome expectancies will not account for the transfer data. By contrast, the data from Experiments $1 \mathrm{~A}, 1 \mathrm{~B}$, and 2 are more in line with Rescorla and Colwill's bidirectional account. According to this alternative, the necessary components for transfer are differential R-O associations and differential stimulus-outcome associations, although these need not be trained concurrently (i.e., in the same task). Its requirements for transfer are simply that the samples (or $\mathrm{S}^{\mathrm{D}} \mathrm{s}$ ) in testing produce different outcome representations and that the available response alternatives have a history of yielding those different outcomes (Urcuioli \& DeMarse, 1997). Thus, differential sample-outcome associations can be established in one training task, whereas the differential $\mathrm{R}-\mathrm{O}$ associations can be established in another, as was the case in Experiments 1A, 1B, and 2. 
But this theory too has its own difficulties-namely, explaining the results of Experiment 3 . Here, responses with differential outcome associations were tested following samples that did not have differential outcome associations. Nonetheless, evidence was obtained for both positive and negative transfer, the "direction" depending on which of two existing sets of comparison responses were replaced by the target responses.

One aforementioned solution to this theoretical dilemma is to suggest that pigeons can predict outcomes by combining different sources of information. In particular, as suggested here and elsewhere (Urcuioli \& DeMarse, 1997), when the samples alone do not reliably signal outcomes (as in the one-to-many training tasks of Experiments 2 and 3), the combination of the sample plus the choice alternatives appearing on the side keys does provide this information. If the outcome expectancies of two-process theory or the outcome representations of the bidirectional account can be generated from such sample-choice compounds, then the mechanism(s) for obtaining transfer of matching to new comparisons could potentially operate.

Interestingly, this proposed modification does not help two-process theory to explain the transfer results of Experiments $1 \mathrm{~A}$ and $1 \mathrm{~B}$. Here, the samples in testing were, as a result of Phase 1 training, reliable predictors of the different outcomes. But the new choice alternatives appearing in the transfer test had been trained singly and off baseline, and, in Experiment 1A, they did not look at all like the choice alternatives in the matching-to-sample training task. Thus, when those new alternatives appeared together in testing, it is unclear how sample-specific expectancies could cue one choice over the other. For that to happen, each outcome expectancy had to have previously acquired discriminative control over one of the two responses.

One possibility, perhaps, is that the different visual information obtained by seeing each individual form $(\mathrm{Ex}-$ periment 1A) or hue (Experiment 1B) during off-baseline training generated different expectancies, given that each stimulus signaled different outcomes for the peck that subsequently occurred to it. If so, differential expectancyresponse links may have formed and, with them, the basis for selection of one choice response over the other in testing. Although clearly ad hoc, especially given the more straightforward account of the results offered by the bidirectional hypothesis, it seems reasonable to suppose that different visual stimuli immediately preceding responding - whether stimuli on the pigeon key or the appearance of very different response manipulanda in a rat chamber-can serve as potent signals for forthcoming response-contingent outcomes.

A rather different theoretical perspective makes no appeal to outcome expectancies or outcome representations. According to this alternative, each sample in a standard differential outcome matching task becomes a signal to peck a particular type of comparison. For instance, pigeons may learn to peck a food-associated stimulus following, say, a vertical sample and to peck a no-food-associated stimulus following a horizontal sample. Later, when new food-associated and no-food-associated choice alternatives appear, vertical and horizontal continue to exercise the same control they had established during training, thus yielding transfer of matching to those new choices. Like the bidirectional hypothesis, this account also anticipates that it should not matter where or when the outcome associations for the new alternatives have been acquired (i.e., on or off baseline). Essentially, all choice stimuli with the same outcome associations become equivalent in the sense that they will readily substitute for one another in new contexts. This alternative is consistent with the transfer results of Experiments 1A, 1B, and 2. However, it cannot handle the results of Experiment 3 because the samples appearing in testing in that experiment did not consistently signal in training that one type of choice alternative (food-associated or no-food-associated) should be pecked. Furthermore, it will not explain why transfer of differential outcome matching occurs so strongly and so readily to new samples trained off baseline (e.g., Peterson, 1984; Urcuioli, 1990) - in other words, to samples that have no history of becoming a discriminative cue for selecting between different types of choice alternatives.

Despite the theoretical uncertainities that remain and the distinct possibility that, with minor modifications, two-process theory and the bidirectional account may be indistinguishable in their predictions, the present data provide yet another example of flexibility in stimulus processing by animals (e.g., Cook, Brown, \& Riley, 1985; Grant \& Spetch, 1993; Urcuioli \& Zentall, 1992). In other words, not only are pigeons clearly sensitive to "what outcomes follow what responses" and to "what outcomes are scheduled following what samples," they also apparently combine sources of information when any single source is an unreliable predictor of what is forthcoming.

\section{REFERENCES}

Carlson, J. G., \& Wielkiewicz, R. M. (1976). Mediators of the effects of magnitude of reinforcement. Learning \& Motivation, 4, 184-196.

ColwiLL, R. M. (1994). Associative representations of instrumental contingencies. In D. L. Medin (Ed.), The psychology of learning and motivation (Vol. 31, pp. 1-72). Hillsdale, NJ: Erlbaum.

Colwill, R. M., \& Rescorla, R. A. (1988). Associations between the discriminative stimulus and the reinforcer in instrumental learning. Journal of Experimental Psychology: Animal Behavior Processes, 14, $155-164$.

Cook, R. G., Brown, M. F., \& Riley, D. A. (1985). Flexible memory processing by rats: Use of prospective and retrospective information in the radial maze. Journal of Experimental Psychology: Animal Behavior Processes, 11, 453-469.

DeLong, R. E., \& WASSERMan, E. A. (1981). Effects of differential reinforcement expectancies on successive matching-to-sample performance in the pigeon. Journal of Experimental Psychology: Animal Behavior Processes, 7, 394-412.

DeMarse, T. B., \& URCUIOL, P. J. (1993). Enhancement of matching acquisition by differential comparison-outcome associations. Journal of Experimental Psychology: Animal Behavior Processes, 19 , 317-326.

Edwards, C. A., Jagielo, J. A., Zentall, T. R., \& Hogan, D. E. (1982). Acquired equivalence and distinctiveness in matching to sample by pigeons: Mediation by reinforcer-specific expectancies. Journal of Experimental Psychology: Animal Behavior Processes, $\mathbf{8}$, 244-259. 
FedorChaK, P. M., \& Bolles, R. C. (1986). Differential outcome effect using a biologically neutral outcome difference. Journal of Experimental Psychology: Animal Behavior Processes, 12, 125-130.

GRANT, D. S., \& SPETCH, M. L. (1993). Analogical and nonanalogical coding of samples differing in duration in a choice-matching task in pigeons. Journal of Experimental Psychology: Animal Behavior Processes, 19, 15-25.

Honig, W. K., Matheson, W. R., \& Dod, P. W. D. (1984). Outcome expectancies as mediators for discriminative responding. Canadian Journal of Psychology, 38, 196-217.

Peterson, G. B. (1984). How expectancies guide behavior. In H. L. Roitblat, T. G. Bever, \& H. S. Terrace (Eds.), Animal cognition (pp. 135148). Hillsdale, NJ: Erlbaum.

RESCORLA, R. A. (1992). Response-outcome versus outcome-response associations in instrumental learning. Animal Learning \& Behavior, 20, 223-232.

RESCORLA, R. A. (1994). Transfer of instrumental control mediated by a devalued outcome. Animal Learning \& Behavior, 22, 27-33.

Rescorla, R. A., \& ColwILl, R. M. (1989). Associations with anticipated and obtained outcomes in instrumental learning. Animal Learning \& Behavior, 17, 291-303.

RODGER, R. S. (1975a). The number of non-zero, post hoc contrasts from ANOVA and error rate: 1. British Journal of Mathematical \& Statistical Psychology, 28, 71-78.

RODGER, R. S. (1975b). Setting rejection rate for contrasts selected post hoc when some nulls are false. British Journal of Mathematical \& Statistical Psychology, 28, 214-232.

SANTI, A., \& Roberts, W. A. (1985). Prospective representation: The effects of varied mapping of sample stimuli to comparison stimuli and differential trial outcomes on pigeons' working memory. Animal Learning \& Behavior, 13, 103-108.

TRAPOLD, M. A. (1970). Are expectancies based upon different reinforcing events discriminably different? Learning \& Motivation, 1 , $129-140$.

URCUIOLI, P. J. (1990). Some relationships between outcome expectancies and sample stimuli in pigeons' delayed matching. Animal Learning \& Behavior, 18, 302-314.

URCU1OLI, P. J. (1991). Retardation and facilitation of matching acquisition by differential outcomes. Animal Learning \& Behavior, 19, $29-36$.

Urcuioli, P. J., \& DeMARSE, T. (1996). Associative processes in differential outcome discriminations. Journal of Experimental Psychology: Animal Behavior Processes, 22, 192-204.

Urcuioli, P. J., \& DeMarse, T. (1997). Some further tests of response-outcome associations in differential-outcome matching-tosample. Journal of Experimental Psychology: Animal Behavior Processes, 23, 171-182.

Urculoli, P. J., DeMarse, T., \& Zentall, T. R. (1998). Transfer actoss delayed discriminations: II. Differences in the substitutability of initial versus test stimuli. Journal of Experimental Psychology: Animal Behavior Processes, 24, 47-59.

URCUIOLI, P. J., \& ZENTALL, T. R. (1992). Transfer across delayed discriminations: Evidence regarding the nature of prospective working memory. Journal of Experimental Psychology: Animal Behavior Processes, 18, 154-173.

Urculoli, P. J., Zentall, T. R., \& DeMarse, T. (1995). Transfer to derived sample-comparison relations by pigeons following many-toone versus one-to-many matching with identical training relations. Quarterly Journal of Experimental Psychology, 48B, 158-178.

(Manuscript received September 2, 1997;

revision accepted for publication January 26, 1998.) 